\title{
REGISTER FOR THE 2007 ASTIN COLLOQUIUM
}

The 2007 ASTIN Colloquium is quickly approaching. The Organizing and Scientific Committees warmly welcome you to the 37th ASTIN Colloquium. This year's event will be held 19-22 June 2007 at the world renowned Disney's Contemporary Resort in Lake Buena Vista, Florida, United States.

Since ASTIN was established in New York City in 1957, the 2007 Colloquium is a celebration of its 50th anniversary. The Casualty Actuarial Society is delighted to host ASTIN as it celebrates its jubilee.

Over 40 papers, authored by both practitioners and academics, will be presented. The papers are available online via the ASTIN Website at www.actuaries.org/ ASTIN2007. Paper topics cover risk management, reserving, and pricing. Pricing issues include applications of credibility, bonus-malus systems, and risk margins, such as those from jump diffusion processes. Several new directions for stochastic modeling of loss reserves are explored. About half the papers concern risk management, subcategories of which include:

- Issues involved in strategic and operational risk;

- Applications of risk modeling, such as insolvency risk, reinsurance, capital needs and allocation, market analysis, and strategic planning of subsidiaries;

- Model building topics, like choice of risk measures, modeling of dependencies, and efficient calculation.

Authors from North America, Australia, and Europe are well represented, but authors from Asian locations such as Beijing, Shanghai, Taiwan, Indonesia, Israel, and Iran are also prominent in this year's list of authors.

Four keynote speakers for the Colloquium will address topics ranging from the history of ASTIN to securitization and its effect on markets. On Wednesday, June 20th, a joint day of CAS and ASTIN meetings, there will be two keynote presentations. Naomi Robbins, an expert on graphically displaying data, will speak in the morning session on the topic of "Visual Presentation of Quantitative Information." That afternoon, past Hachemeister Prize winner Morton Lane, President of Lane financial LLC, will be addressing the issue of "Does Securitization Threaten to Replace, or Improve, Traditional Markets?" On Friday morning, Past President of the CAS Stephen P. D'Arcy, Professor of finance and the John C. Brogan Faculty Scholar in Risk Management and Insurance at the University of Illinois at Urbana-Champaign, will present a thought-provoking discussion of "ASTIN's Next Greatest Contributions." Friday's session will 
conclude with a much anticipated presentation by the world renowned actuary Hans Bühlmann, Professor of Mathematics at the Swiss Federal Institute of Technology in Zurich, providing his insight on "The History of ASTIN".

The highlights of the Social Program include an afternoon and evening at the Kennedy Space Center on Thursday and the $50^{\text {th }}$ Anniversary Gala to be held Friday evening at EPCOT ${ }^{\circledR}$ Center. Both events promise to be remembered for years to come.

For more information on the 2007 ASTIN Colloquium, visit the CAS website at www.casact.org, or the ASTIN Website at www.actuaries.org/ASTIN2007. 